\title{
CYCLIC BEHAVIOR OF INTERIOR BEAM-COLUMN CONNECTIONS IN NON- SEISMIC RC FRAMES AT DIFFERENT LOADING RATES
}

\author{
Rajesh P. Dhakal \\ Corresponding author: Senior Lecturer, Department of Civil Engineering, University of Canterbury, Post \\ bag 4800, Christchurch 8020, New Zealand, E-mail: rajesh.dhakal@,canterbury.ac.nz \\ Tso-Chien Pan \\ Professor \& Director, Protective Technology Research Centre, Nanyang Technological University, \\ 50 Nanyang Avenue, Singapore 639798, E-mail: cpan@ntu.edu.sg
}

\begin{abstract}
This paper provides an insight into the response of non-seismic reinforced concrete (RC) building frames to excitations of different frequencies through experimental investigation. The results of cyclic loading tests of six full-scale RC beam-column sub-assemblies are presented. The tested specimens did not have any transverse reinforcement inside the joint core, and they were subjected to quasi-static and dynamic loading with frequencies as high as $20 \mathrm{~Hz}$. Some important differences between the cyclic responses of non-seismic and ductile RC frames are highlighted. The effect of excitation frequency on the behavior of non-seismic joints is also discussed. In the quasi-static tests, shear deformation of the joint panel accounted for more than $50 \%$ of the applied story drift. The test results also showed that higher-frequency excitations are less detrimental than quasi-static cyclic loads, and non-seismic frames can withstand a higher load and a larger deformation when they are applied faster.
\end{abstract}

Keywords: Non-seismic; high-frequency; loading rate; shear failure; joint deformation; residual stiffness

\section{Introduction}

Beam-column joints are important components of a building frame. Joints in seismically designed $\mathrm{RC}$ frames are provided with sufficient transverse reinforcement to ensure that the joint is stronger than the adjoining members. Strict adherence to seismic design method leads to a strong-column weak-beam type frame, the overall behavior of which is mainly governed by the beams. On the other hand, RC frames designed only for the gravity loads lack transverse hoops inside the joint core and have sparsely spaced lateral ties in the columns, thereby rendering the columns and the joints vulnerable to lateral action. Such building frames are common in regions of low or moderate seismicity, and hence frames/joints with such features are hereafter referred to as non-seismic frames/joints. When subjected to seismic excitations, the relative contributions of the joint, beam and column to the overall behavior and the ultimate failure mechanism of such non-seismic frames may differ from those of seismically designed ductile frames. Although not particularly designed to resist lateral actions, buildings in non-seismic regions may still have to withstand high frequency ground shocks induced by nearby explosion or construction vibrations and low frequency ground motions generated by earthquakes. This paper discusses the response of non-seismic frames to lateral excitations of different frequencies.

A wealth of literature addressing seismic behavior of RC beam-column joints [Bertero and Popov 1977, Otani et al 1985, Park 2002] is available. Results of quasi-static tests on ductile RC connections have been reported extensively [Otani et al 1984, Wong et al 1990, Oka and Shiohara 1992]. Some have also investigated the quasi-static response of beam-column joints with non-ductile details [Beres et al 1992, Hakuto et al 2000], and have found that such frames 
may have the undesirable strong-beam weak-column configuration and may be vulnerable to joint shear failure when subjected to a lateral load. Dhakal and Pan [2003b] have explained in detail the procedures for conducting high-speed cyclic loading tests on beam-column joints. They have highlighted problems that may arise due to unusually high loading rate and have also explained ways of tackling these problems. Notwithstanding, there is little information available on the response of RC frames to high-frequency cyclic excitations. Aiming to narrow this gap, this paper presents the results of quasi-static and dynamic tests on non-seismic RC beam-column frames, and manifests the effect of loading speed on the behavior of non-seismic joints.

Some features inherent in the specimen details and the loading protocols of the experimental program reported in this paper make it novel. The specialties lie in the lack of transverse reinforcement inside the joint cores of the specimens tested and the high-frequency dynamic loading adopted in the tests. The reinforcement details of the specimens resemble those of non-seismic RC frames, making the quasi-static test results useful to understand the response of building frames of non-seismic regions to lateral cyclic actions. For the high-frequency dynamic tests, the results are also important to understand the response of non-seismic RC frames to explosion-induced ground shocks. This study would also provide a platform to derive guidelines for the design of new buildings and for the retrofitting of existing buildings in nonseismic regions.

\section{Experimental Program}

The tested beam-column sub-assemblies included specimens of two types, namely type 1 and type 2. The dimensions and reinforcement layouts of the two types are illustrated in Figs. 1a and $1 \mathrm{~b}$, respectively. All specimens had a $3.7 \mathrm{~m}$ high column and a $5.4 \mathrm{~m}$ long beam. The beam in all specimens had $300 \times 550 \mathrm{~mm}$ cross-section, whereas the column cross-section was $350 \times$ $500 \mathrm{~mm}$ in type 1 and $400 \times 400 \mathrm{~mm}$ in type 2 specimens. All specimens had eight \#8 $(25 \mathrm{~mm}$ diameter) bars in the column whereas the number of \#10 (32 $\mathrm{mm}$ diameter) bars in the beam was 7 ( 5 at the top 2 at the bottom) in type 1 and 9 (6 at the top and 3 at the bottom) in type 2 specimens. The two-legged \#3 (10 mm diameter) beam stirrups were spaced at $200 \mathrm{~mm}$ in all specimens, and the \#3 column ties (two legs in type 1 and three legs in type 2) had a spacing of $150 \mathrm{~mm}$. For convenience, the specimens were cast in horizontal position. The average distance between the outermost reinforcing bar and the steel formwork was $27.5 \mathrm{~mm}$ in the beams and $42.5 \mathrm{~mm}$ in the columns. As shown in Fig. 1, no hoops inside the joint core, the column main bars and the beam bottom bars spliced near the joint were features of the specimens. The concrete used in the specimens was of normal strength, and high strength steel bars were used as longitudinal reinforcement whereas the stirrups consisted of normal strength steel bars. The average concrete compressive strength for the type 1 specimens was $31.7 \mathrm{MPa}$ whereas that for the type 2 specimens was $32.8 \mathrm{MPa}$. Similarly, the average yield strengths of the \#10, \#8 and \#3 bars were 538.0 MPa, 537.6 MPa and 363.7 MPa, respectively.

One of the specimens connected to the test rig is shown in Fig. 2. Note that only three supports were perfectly-pinned whereas the support at the bottom of the column partially restrained the rotation. Measured between the supports, the effective height of the column was $3.2 \mathrm{~m}$ and the effective length of the beam was $6.0 \mathrm{~m}$. The columns were axially compressed through two prestressing tendons and were subjected to displacement controlled cyclic loadings. The specimens were subjected to an axial compression which was intended to remain constant but was found to vary between 590 and $700 \mathrm{kN}$ in type 1 specimens and between 555 and $660 \mathrm{kN}$ in type 2 specimens (approximately $0.106 f_{c}^{\prime} A_{g}-0.126 f_{c}^{\prime} A_{g}$ ). To facilitate the application of the 
axial compression, the column-top was kept stationary and the displacement cycles were applied at the beam-tips. The displacements applied at an instant at the two beam-tips were equal in magnitude but opposite in direction.

The experimental program adopted three different loading protocols classified as quasistatic (QS), constant-frequency-dynamic (CFD) and variable-frequency-dynamic (VFD) loadings, based on the frequency of the displacement cycles applied. The displacement amplitude, the corresponding story drift, number of repeated cycles of a constant story drift, the cyclic frequency and the corresponding loading speed of the displacement cycles throughout the loading history of the QS, CFD and VFD tests are listed in Table 1. The story drift is computed by dividing the summation of the displacements of the two beam-tips by the equivalent beam length. In the QS tests, the story drift was increased gradually in steps from $0.25 \%$ radian to $2.0 \%$ radian with a $0.25 \%$ radian increment in each step. To avoid data congestion, the increment was changed to $0.5 \%$ radian after reaching $2.0 \%$ radian story drift until the specimen failed. The first loading step corresponding to $0.25 \%$ radian story drift had only one cycle whereas the loading steps thereafter consisted of three repeated cycles to observe strength degradation, if any. In the CFD tests, the specimens were tested under cyclic displacements applied at two cycles per second; i.e. $2 \mathrm{~Hz}$. Maintaining the cyclic frequency constant, the magnitude of the displacement cycles were gradually increased in the same manner as in the QS tests.

In the VFD tests, the specimens were subjected to cyclic displacements with frequency gradually changing from 20 cycles per second $(20 \mathrm{~Hz})$ to 2 cycles per second $(2 \mathrm{~Hz})$. The displacement histories used in the VFD tests started with 10 cycles of $\pm 2 \mathrm{~mm}$ amplitude applied at $20 \mathrm{~Hz}$. This was followed by 10 cycles each of \pm 5 and $\pm 10 \mathrm{~mm}$ amplitudes applied at $15 \mathrm{~Hz}$ and $10 \mathrm{~Hz}$, respectively. These 30 high-frequency cycles were followed by larger loading steps similar to those in the QS and CFD tests in terms of the displacement amplitude and number of repeated cycles, but these larger displacement cycles in the VFD tests were applied at the highest frequencies possible. Consequently, the cyclic frequency gradually decreased with an increase in the amplitude of the displacement cycles. The loading applied in the VFD tests was hence a combination of higher order vibration modes that constitute high frequency but small displacement oscillations and lower order vibration modes which are characterized by low frequency but large displacement oscillations. The loading sequence hence qualitatively included the free-vibration and forced-vibration responses of $\mathrm{RC}$ frames due to impulse type ground shocks induced by explosions [Dhakal and Pan 2003a]. Note that the cycles corresponding to story drifts equal to and more than $3.0 \%$ radian could be applied only at $2 \mathrm{~Hz}$, similar to those in the CFD tests. To highlight the difference between the specimens' behaviors during the conventional pseudo-dynamic tests and high-frequency dynamic tests, one specimen of each type was subjected to each of these three loading patterns. Following the specimen type and the loading pattern applied, the six tests were named as QS1, CFD1, VFD1, QS2, CFD2, and VFD2, respectively.

The forces and displacements applied at the beam-tips were measured with load-cells and displacement transducers in-built in the loading actuators. Similarly, a transducer and a load-cell integrated in the actuator at the column-top measured the lateral displacement (if any) and the horizontal reaction. As an unknown moment exists at the bottom support that is not perfectlypinned, the horizontal force at the column-top cannot be derived by equilibrium and hence needs to be measured directly. Moreover, the direct measurement of the column-top reaction also eschews the inertial force from affecting the story shear force data [Dhakal and Pan 2003b]. A dial-gauge was used to measure the movement of bottom support, which when combined with the lateral displacement measured at the column-top would enable the estimation of the rigid body 
rotation, which would then be deducted from the story drift derived from the beam-tips displacements. The variation of axial load was monitored using two external load cells in the two prestressed tendons. Two pi-gauges were attached diagonally across the joint surface (see Fig. 2) to record elongation or shortening of the two diagonals, which would then be used to compute the shear-deformation of the joint panel. A grid of strain gauges was used to monitor the strains experienced by the longitudinal and transverse reinforcing bars of the adjoining members near the joint panel. The loading actuators, measuring sensors and data loggers were carefully selected and verified to ensure that the response measurement and data acquisition at a high sampling frequency was possible to cater to the needs of the high-frequency tests [Dhakal and Pan 2003b].

\section{Predicted Failure Mode and Capacity}

The specimens were full-scale replicas of beam-column joints of $\mathrm{RC}$ frames in low-rise buildings in a low-seismicity region. Consequently, the reinforcement details of the specimens are similar to those found in buildings in New Zealand that were designed and built in the 1970s [Hakuto et al 2000] and also in buildings in North America that were designed for gravity loads only [Beres et al 1992]. As seismic design method is not practiced in low-seismicity regions, the specimens may not be of the usual strong-column weak-beam status, and the failure mode might also be different from the plastic hinging modes commonly observed in ductile frames. The capacity of a beam-column sub-assembly is attributed to the least of the ultimate strengths of three individual components, namely the beam, the column and the joint. The failure mode and the capacity of the specimens are theoretically predicted as shown in Table 2 according to the New Zealand standard [NZS 3101:1995] and the ACI code [ACI 352R-91] criteria.

The ratio of beam height to the diameter of column bar in all specimens was 22, which satisfied the development length requirements of NZS 3101:1995 and ACI 352R-91 standards for ductile frames. On the other hand, the ratios of column depth to the diameter of beam longitudinal bar in type 1 and type 2 specimens are 15.6 and 12.5, respectively, none of which satisfied the development length requirements for ductile frames recommended by either of NZS 3101:1995 (approximately 36 for the measured values of material strengths) or ACI 352R-91 (20) standards. Based on the values of measured average material strengths, the flexural capacities of the beam and the column are computed based on section analysis assuming the strain in the extreme compression fiber to be 0.0035. In calculating the flexural and shear strengths of the column, the effect of the normal (i.e. axial) force is taken into account. Note the different amount of reinforcing bars at the bottom and the top of the beam, which engenders two different flexural strengths for the beam depending on whether the bottom or top fibers are in tension, indicated respectively with $(+)$ and $(-)$ in Table 2 .

To identify the weaker member, the story shear forces induced when the beam and the column attain their capacities are computed and compared with each other. As shown in Fig. 3a, the story shear force corresponding to the beam flexural capacity is derived based on the equilibrium using the flexural strengths of the beam-sections at the two sides of the joint. Note that this might slightly overestimate the story shear force, as the beam sections at the two sides of the joint may not necessarily reach their ultimate flexural capacities at the same time. As the maximum moment in the column always occurs at the column-joint interface, dividing the column flexural capacity by the projection of the column beyond the joint gives the corresponding story shear force (see Fig. 3b). As expected, the story shear force corresponding to the column capacity is less than that corresponding to the beam capacity (see Table 2), thereby revealing that the specimens are of weak-column strong-beam type, and plastic hinges, if any, will appear first in the columns. 
Nevertheless, this does not necessarily predict that the overall sub-assembly failure will result from the flexural failure of the column, particularly if the joint is weaker than the column. As shown in Table 2, the nominal horizontal joint shear is computed as $1.25 \sqrt{ } f_{c}^{\prime}$ and as $0.2 f_{c}^{\prime}$, where $f_{c}$ is the compressive strength of concrete. Not that these expressions consider the allowable joint shear stress as a function of concrete compressive strength only and do not include any parameter related to the amount and strength of transverse hoops. Although these expressions are provided in ACI 352R-91 and NZS 3101:1995 to estimate the allowable shear stress in ductile joints that have sufficient shear reinforcement as recommended by the corresponding codes, the shear stress in the joints of the specimens tested may not actually reach $0.2 f_{c}$, due to the lack of transverse hoops inside the joints [Hakuto et al 2000]. The story shear force corresponding to the nominal joint shear is computed as shown in Fig. 3c. Note that although the nominal joint shears in both types of specimens are almost equal as they are made of almost similar grades of concrete, a larger joint cross-section area makes the corresponding story shear force larger in type 1 specimens. As can be seen in the table, the story shear forces corresponding to the nominal joint shear of both specimen types are less than those corresponding to the column capacities, indicating that the joint is the weakest component of the sub-assemblies. In other words, the specimens' capacities will depend on their joint shear capacities, and the specimens are expected to undergo joint shear failure before a plastic hinge is formed in the column.

As the expressions for $V_{c}$ in Fig. 3 indicate, the fixity of the bottom support tends to increase the story shear forces corresponding to the beam and joint capacities but does not affect the story shear force corresponding to the column capacity. The moment reaction $M_{0}$ at the bottom support is different for the three cases, but the order of their magnitudes is expected to be the same as that of the corresponding story shear force magnitudes. Note that the values of story shear forces tabulated in Table 2 do not include the effect of $M_{0}$ as its magnitude is not known at this stage. This reduces the story shear forces corresponding to the beam and joint capacities.

\section{Test Results}

\section{Damage pattern and failure mechanism}

In all tests, crack initiation and propagation were monitored as closely as possible. At the same time, the displacement cycles were not interrupted too often in the high-frequency dynamic tests in order to observe the frequency effect precisely. During the quasi-static tests, cracks were marked at the positive and negative peaks of the first and the third cycles of each loading step. However in the CFD tests, the displacement cycles were not interrupted, and the damage inspection was performed only after the $2.5 \%$ radian story drift cycles had been applied. Whereas in the VFD tests, the loading was paused after each step until the first crack could be noticed. This was to ascertain if the very high frequency but small amplitude excitations would inflict any damage on the specimens and also to check if there is any delay in cracking due to an increase in the cyclic frequency. Thereafter, the cyclic loading was not stopped until after completing the $2.5 \%$ radian story drift cycles. In the high-frequency tests, the completion of the $2.5 \%$ radian story drift cycles was selected for damage inspection because the specimens showed the first sign of failure at this instant during the pseudo-dynamic tests. In all tests, from the $3.0 \%$ radian story drift cycles until failure, the loading was stopped at the end of each step and the physical condition of the specimen was inspected before proceeding to the next loading step.

Diagonal cracks appeared in the joint panel surfaces before any cracks could be seen in the adjoining members. In the QS tests, the first pair of diagonal cracks could be noticed after the $0.25 \%$ radian story drift cycles were applied, whereas the first diagonal cracks were visible after 
the $0.5 \%$ radian story drift cycles in the VFD2 test and after the $0.75 \%$ radian story drift cycles in the VFD1 test. As the loadings were continuous until 2.5\% radian story drift, the crack initiation in the CFD tests and crack propagation in the CFD and VFD tests could not be monitored. On further loading of the QS specimens, a few uniformly distributed flexural cracks emerged in the beams and the columns, and some new cracks emerged randomly in the joint panel surfaces. Nevertheless, these new distributed cracks were much thinner compared to the first pair of diagonal cracks, which opened and closed alternately following the direction of the cyclic displacement. In the high-frequency tests, opening and closing of the upper column-joint interface could be observed during large displacement cycles. Although one of the QS tests was terminated after the $2.5 \%$ radian story drift cycles, the specimens could be subjected to as high as $4.0 \%$ radian story drift cycles in the high-frequency tests. The damage on the specimens at the end of the six tests is illustrated in the photographs in Fig. 4. When the tests were terminated, most of the concrete cover had spalled off from the joint surface, and the reinforcing bars were exposed. The columns had a few cracks, and agreeing with the strong-beam weak-column status, the beams had even fewer cracks.

\section{Story shear force vs. story drift relationships}

Fig. 5 shows the cyclic relationships between the story shear force and the story drift obtained in the six tests. Here, the story shear force is the horizontal reaction force recorded by the load cell at the column-top, and the story drift is the angle made by the line joining the beamtips with respect to the original beam axis. Note that the hysteresis loops of the QS specimens are smooth whereas those of the CFD and VFD specimens show slight undulations. This is caused by the high data sampling frequency adopted in the high-frequency tests [Dhakal and Pan 2003b]. The degradation of the story shear force in the three repeated cycles was severer at a larger story drift in the QS tests, but it varied randomly during the CFD and VFD tests signaling no correlation with the applied story drift. In the QS tests, loading was terminated after the story shear force degraded by more than $20 \%$ during the three cycles. However, the failure point could not be precisely determined based on this criterion in the high-frequency tests, and the tests were terminated after the specimens were visibly severely damaged. Thus, the CFD and VFD tests could be continued until the story drift reached $4.0 \%$, whereas the specimens in the QS tests failed at $2.5 \%-3.0 \%$ story drift.

The hysteresis curves did not show any yielding plateau, and the responses were brittle with the story shear force starting to soften immediately after attaining the peak value. The cyclic loops showed a severe pinching with small energy absorption. The stiffness at the beginning of unloading and reloading loops is much smaller than the initial stiffness in these tests. This is in contrast to cyclic test results of ductile frames [Park 2002], where the tangential stiffness at the beginning of unloading and reloading loops is apparently close to the initial stiffness. This is because a plastic hinge invariably forms in such ductile frames, and the overall response is controlled by the reinforcing bars in the plastic hinge. On the other hand, no plastic hinges were formed in the tested non-seismic connections. It can hence be argued that the overall behavior was governed by the concrete in the joint panel, which is again supported by the fact that unloading loops heading towards the origin is an inherent feature of concrete cyclic response.

The story shear force corresponding to the allowable joint shear stress recommended by the ACI 352-91 [1991] and that corresponding to the flexural capacity of the column are also marked in Fig. 5. The expression recommended by the NZS 3101:1995 to estimate the allowable joint shear stress gives a lower value (see Table 2), which was exceeded in all tests. Note that the 
peak story shear force was much less than the story shear force corresponding to the column flexural capacity but was close to that corresponding to the joint shear capacity in all tests.

\section{Stiffness degradation}

Residual stiffness is an important parameter in assessing the condition of a structure after a load has been applied. Stiffness degradation gives a qualitative indication of overall structural damage and also about the usability of a structure. Figs. 6a and $6 \mathrm{~b}$ plot the degradation of shear stiffness with respect to the applied story drift for the type 1 and type 2 specimens, respectively. In these plots, structural stiffness at each loading step is taken as the average of the secant stiffness at the opposite peaks of the first displacement cycle corresponding to that story drift (see Fig. 6c). As the columns are larger in type 1 specimens, the initial shear stiffness of type 1 specimens was higher than that of type 2 specimens. The trend of stiffness degradation was very similar in all specimens. Sustained gradual degradation of shear stiffness could be observed throughout the loading range until failure. The stiffness of the VFD specimens at a story drift less than $0.5 \%$ radian was higher than those of the QS and CFD specimens. The difference between the residual stiffness of the QS and CFD specimens gradually increased with the increase in story drift, and after $1.25 \%$ radian story drift, the stiffness attenuation curves of the CFD and VFD specimens traveled together. Note that the residual stiffness of all specimens at the end of the tests was almost the same regardless of the loading speeds.

\section{Joint panel response}

As the weakest component of the specimens was the joint (see Table 2), all specimens experienced joint shear failure before the formation of any plastic hinge in the column. Significant deformation of the joint panel was visible in the specimens even after the tests, and the major share of the applied story drift must have been consumed by the shear deformation of the joint panel. For further verification, the contribution of the joint panel shear deformation to the overall story drift is plotted against the applied story drift in Figs. 7a and $7 \mathrm{~b}$ for the type 1 and type 2 specimens, respectively. As mentioned earlier, shear strain of the joint panel was monitored using two pi-gauges attached diagonally on the joint surface. These gauges recorded the elongation and shortening of the diagonals of a joint panel. As shown in Fig. 7c, the shear strain of the joint panel $\gamma$ could be easily computed as the width $a$, the height $b$, and the diagonal $D$ of the joint panel were measured in advance. Nevertheless, pi-gauge readings could not be taken after the spalling of concrete from the joint surface, as the attached gauges were either disrupted or dislodged by the falling pieces of concrete. Consequently, shear deformation of the joint panels could not be computed for story drifts larger than $2.5 \%$ radian.

All specimens showed a common trend; i.e. percentile contribution of the joint panel shear deformation increased with an increase in the applied story drift. In the case of QS2, it accounted for as much as $70 \%$ of the applied story drift at failure. In specimens subjected to highfrequency loading, as high as $40 \%$ of the applied story drift was consumed by the joint panel shear deformation. Except at $0.75 \%$ radian story drift in the type 2 series, the contribution of the joint panel shear deformation was the least for the CFD specimens. Furthermore, barring some discrete exceptions, the joint panel shear deformation's contributions towards the story drift was the highest in the VFD specimens in a small story drift range and in the QS specimens in a larger story drift range. 


\section{Discussions \\ General}

In all tests, the specimens were damaged mainly during the larger displacement cycles. The VFD specimens did not show any crack during the very-high frequency but small amplitude displacement cycles representative of higher order vibration modes. No visibly noticeable movements of the joint panel occurred during these small displacement cycles, which were applied so fast that the specimen might not have had enough time to respond.

As mentioned earlier, the maximum story shear forces observed in the tests were comparable to the story shear force corresponding to the allowable joint shear stress recommended by the ACI 352R-91 [1991], which is even higher than that recommended by the NZS 3101-95 [1995]. Note that the axial compression applied at the top of the specimens might have enhanced the joint shear strength to some extent. While the recommendations of these standards are meant specifically for ductile joints with sufficient confining hoops, the tested specimens completely lacked transverse reinforcement inside the joint core.

Whereas the difference between the story shear forces at the $1^{\text {st }}$ and the $3^{\text {rd }}$ cycles varied randomly without showing any correlation with the applied story drift in the high-frequency tests, the shear stiffness showed a gradual decrease with an increase in the applied story drift in all tests. Furthermore, regardless of the loading speed, the residual stiffness of all specimens was almost equal when the tests were terminated following severe damage. These observations suggest that residual stiffness might serve as a more representative parameter to track damage and failure of such joints regardless of the loading speed.

Also of interest is the unusual large contribution of joint panel shear deformation to the story drift observed in the tests. In seismically designed RC frames, the flexural deformation of the adjoining members account for a larger part of the overall deformation, and the contribution of joint shear deformation to the story drift rarely exceeds $20 \%$ [Otani et al 1985]. In gravitydesigned connections tested by Aycardi et al [1994] the joint deformation accounted for about $25 \%$ of the story drift in spite of yielding of longitudinal bars. On the other hand, the joint shear deformation at the end of the current tests accounted for more than $50 \%$ of the story drift in the QS tests and upto $40 \%$ of the story drift in the CFD and VFD tests. These results indicate that joint deformation must be included in the design and analysis of non-seismic joints [Ghobarah and Biddah 1999], and the rigid-joint assumption normally adopted in analyzing ductile frames should not be used if the joints do not fulfill the seismic design requirements.

\section{Effect of Loading Speed}

In all specimens, cracks emerged first in the joint panel, but the first crack appeared at a lower story drift in the QS tests than in the VFD tests. As the CFD and QS tests were interrupted only after completing the $2.5 \%$ radian story drift cycles, physical conditions of the joint panels of all specimens at that instant are shown in Fig. 8 for comparison. As can be observed, specimens in the QS tests were more severely damaged than those in the CFD or VFD tests. However, physical conditions of the CFD and VFD specimens at this stage were almost similar, and it is difficult to determine which one had undergone severer damage. The joint panel deteriorated more in the QS tests, and the specimens had comparatively more cracks on the beam and column in the QS tests than in the CFD or VFD tests. The delay of initial cracking in the VFD tests, and the evolution of apparently more cracks in the QS tests may have been caused by the increase of cracking strength of concrete at a higher loading rate [Klepaczko and Brara 2001].

The prominent features including the strength, stiffness, deformability and failure modes of the six specimens tested are summarized in Table 3. Owing to the additional 30 displacement 
cycles and the variable frequency adopted in the VFD tests, direct comparison of the VFD test results with the QS and CFD tests may not yield any quantitative conclusion. However, it can provide information on qualitative interdependency between the loading rate and the response parameters. On the other hand, results of the QS and CFD tests can be directly compared to extract the effect of loading rate as the CFD test followed exactly the same loading sequence as in the QS tests but at a constant frequency of $2 \mathrm{~Hz}$. Regardless of the loading speed, all specimens suffered joint shear failure before the formation of a plastic hinge in the column. Note the enhanced deformability in the high-frequency tests. Failure correlated with $20 \%$ reduction of story shear force in three repeated cycles meant that the quasi-static specimens QS1 and QS2 failed after completing $2.5 \%$ and $3.0 \%$ story drift cycles respectively. Shear degradation varied randomly in high-frequency tests and this definition of failure could not be applied to other specimens. Visibly severe damage prompting the termination of loading occurred after $4.0 \%$ story drift cycles in the CFD specimens. This can be attributed to the increase of ductility and energy absorption capacity of concrete with increasing strain rate [Cadoni et al 2000].

The story shear capacities of the CFD specimens were about $15 \%$ higher than those of the QS specimens. As the peak story shear forces in the tested specimens corresponded to their joint shear capacities which depend only on the concrete strength, the higher story shear capacity of CFD specimens is due mainly to the increase in the strength of concrete at a higher loading rate [Filiatrault and Holleram 2001]. Note that the shear stiffness of the QS and CFD specimens in the small displacement range was comparable to each other, whereas that of the VFD specimens was about 30\% more. Although the stiffness at low story drifts may not mean much as it is dependent on shrinkage and curing conditions, the difference between the stiffness of the VFD and other specimens is too large to overlook. Also interesting was the trend of the residual stiffness in the CFD tests in a larger story drift. In terms of the residual stiffness, the CFD specimens departed from the QS specimens and approached towards the VFD specimens as the story drift increases. Finally, at story drifts larger than $2.0 \%$ radian, the residual stiffness of the CFD and VFD specimens were close to each other whereas that of the QS specimens was about $15 \%$ less. Recall the variation of loading speeds of the CFD and VFD tests (see Table 1). The loading speed increased gradually with the cyclic amplitude in the CFD tests, whereas the increasing amplitude and decreasing cyclic frequency kept the loading speed within a small range in the VFD tests. Hence, the loading speed of the CFD tests was much smaller than that of the VFD tests in the small story drift range and comparable to that of the VFD tests in the larger story drift range; a trend similar to the residual stiffness observed in the CFD and VFD tests. As the induced strain rate depends on the loading speed, the aforementioned observation is in agreement with the fact that the stiffness of concrete increases with an increase in the strain rate [Filiatrault and Holleram 2001].

Next, the joint panel shear deformations induced in different tests at different story drift levels are compared. The joint panel shear deformation was less in the CFD tests than in the QS tests throughout the loading range in both types, and the difference was as high as $50 \%$. This might be attributed partly to an increase in stiffness at a higher loading rate and partly to a larger participation of local vibration modes in the overall response when high frequency excitations are applied [Dhakal and Pan 2003a]. When the cyclic displacement was applied slowly, the subassembly deformed in its global mode, thereby distorting the joint panel to the maximum possible extent. On the other hand, the high-frequency displacement cycles also triggered local oscillations of the beams and columns in addition to the global deformation modes which have frequencies closer to the cyclic frequency of the applied loading. These local vibration modes affect only the members, and they would obviously disturb the joint panel less than the global 
deformation modes of the sub-assembly would. But surprisingly, the VFD specimens deformed more than the CFD specimens throughout the loading range, and also more than the QS specimens in the small drift range. Although the authors could not fully explain this phenomenon, they are of the opinion that the fatigue effect of the additional 30 small displacement cycles might be responsible for the larger joint deformation in the VFD specimens.

\section{Concluding Remarks}

Six beam-column sub-assemblies representative of non-seismic RC frames were tested under quasi-static and dynamic loading consisting of displacement cycles of frequency as high as $20 \mathrm{~Hz}$. The specimens, though devoid of confining hoops inside the joints, could withstand story shear forces that correspond to joint shear stresses comparable to the allowable shear stress in ductile joints manifested in the ACI 352R-91 and the NZS 3101-95 standards. The tested specimens had axial compression which tends to enhance the joint shear strength, and one should be cautious while extrapolating results of these tests for other conditions in which considerable column compressive load might not be present. The results showed that the shear stiffness of such non-seismic joints consistently degrade with an increase in the applied story drift regardless of the loading speed, and hence might serve as an appropriate parameter reflecting the damage levels. The contribution of joint panel shear deformation to the overall story drift in the tested non-seismic connections was as high as $50 \%$, which is much larger than that recorded for ductile joints in literature. Hence, rigid joint assumption is not suitable for non-seismic RC frames, and it is strongly recommended to take into account the joint deformation in analyzing non-seismic RC frames. The experimental observations indicated that cracking is delayed, and structures incur less damage when subjected to a higher frequency excitation. Based on the test results, it may also be concluded that the strength, ultimate drift and stiffness of non-seismic RC joints increase when the loading is applied faster. The dominance of joint panel shear deformation in the story drift will be less pronounced if the loading rate is higher.

\section{References}

1. ACI-ASCE Committee 352 (1991), Recommendations for Design of Beam-Column Joints in Monolithic Reinforced Concrete Structures (ACI 352R-91), American Concrete Institute.

2. Aycardi, L.E., Mander, J.B. and Reinhorn, A.M. (1994), "Seismic resistance of reinforced concrete frame structures designed only for gravity loads: Experimental performance of subassemblages", ACI Structural Journal, 91 (5), 552-563.

3. Beres, A., El-Borgi, S., White, R.N. and Gergely, P. (1992), Experimental results of repaired and retrofitted beam-column joint tests in lightly reinforced concrete frame buildings, Technical Report NCEER-92-0025, Cornell University.

4. Bertero, P.P. and Popov, E.P. (1977), "Seismic behavior of ductile moment resisting reinforced concrete frames", Reinforced Concrete Structures in Seismic Zones (SP-53), American Concrete Institute, Michigan, 247-291.

5. Cadoni, E., Labibes, K., Berra, M., Giangrasso, M. and Albertini, C. (2000), "High-strain-rate tensile behaviour of concrete", Magazine of Concrete Research, 52 (5), 365-370.

6. Dhakal, R.P. and Pan, T.C. (2003a), "Response characteristics of structures subjected to blasting induced ground motions", International Journal of Impact Engineering, 28 (8), 813828.

7. Dhakal, R.P. and Pan, T.C. (2003b), "Characteristics of high-speed cyclic test of beamcolumn joints”, ACI Structural Journal, 100 (2), 188-196. 
8. Filiatrault, A. and Holleran, M. (2001), "Stress-strain behavior of reinforcing steel and concrete under seismic strain rates and low temperatures", Materials and Structures, 34 (238), 235-239.

9. Ghobarah, A. and Biddah, A. (1999), "Dynamic analysis of reinforced concrete frames including joint shear deformation", Engineering Structures, 21 (11), 971-987.

10. Hakuto, H., Park, R. and Tanaka, H. (2000), "Seismic load tests on interior and exterior beam-column joints with substandard reinforcing details", ACI Structural Journal, 97 (1), 1125.

11. Klepaczko, J.R. and Brara, A. (2001), "An experimental method for dynamic tensile testing of concrete by spalling", International Journal of Impact Engineering, 25 (4), 387-409.

12. NZS 3101-95 (1995), Concrete Structures Standard - The Design of Concrete Structures, Standards New Zealand.

13. Oka, K. and Shiohara, H. (1992), "Tests of high-strength concrete interior beam-column joint subassemblages", Proceedings of the $10^{\text {th }}$ World Conference on Earthquake Engineering, Balkema, Rotterdam, 3211-3217.

14. Otani, S., Kobayashi, Y. and Aoyama, H. (1984), "Reinforced concrete interior beam-column joints under simulated earthquake loading", First US-NZ-Japan Seminar on Design of Reinforced Concrete Beam-Column Joints, California, pp. 48.

15. Otani, S., Kitayama, K. and Aoyama, H. (1985), "Beam bar bond stress and behaviour of reinforced concrete interior beam-column connections", Second US-NZ-Japan Seminar on Design of Reinforced Concrete Beam-Column Joints, Tokyo, pp. 40.

16. Park, R. (2002), "A summary of results of simulated seismic load tests on reinforced concrete beam-column joints, beams and columns with substandard reinforcing details", Journal of Earthquake Engineering, 6 (2), 147-174.

17. Wong, P.K.C., Priestley, M.J.N. and Park, R. (1990), "Seismic resistance of frames with vertically distributed longitudinal reinforcement in beams", ACI Structural Journal, 87 (4), $188-198$.

\section{List of Tables}

Table 1 Features of cyclic loadings applied in different tests

Table 2 Prediction of capacities and failure modes of the specimens

Table 3 Summary of test results

\section{List of Figures}

Figure 1 Specimen details

Figure 2 A specimen connected to the test rig

Figure 3 Story shear forces corresponding to failure of different components

Figure 4 Damaged specimens at the end of the tests

Figure 5 Story shear force vs. story drift relationships

Figure 6 Variation of story shear stiffness with the story drift

Figure 7 Variation of joint panel shear deformation with the story drift

Figure 8 Physical conditions of the specimens after applying the $2.5 \%$ radian story drift cycles 


\begin{tabular}{|c|c|c|c|c|c|c|c|}
\hline \multirow{2}{*}{$\begin{array}{l}\text { Displacement } \\
\text { amplitude, mm } \\
\text { (1) }\end{array}$} & \multirow{2}{*}{$\begin{array}{c}\text { Story drift, } \\
\% \\
(2)\end{array}$} & \multicolumn{2}{|c|}{ Number of cycles } & \multicolumn{2}{|c|}{ Cyclic frequency, $\mathrm{Hz}$} & \multicolumn{2}{|c|}{ Loading speed, $\mathrm{mm} / \mathrm{s}$} \\
\hline & & $\begin{array}{c}\text { QS, CFD } \\
\text { (3) }\end{array}$ & $\begin{array}{l}\text { VFD } \\
(4)\end{array}$ & $\begin{array}{l}\text { CFD } \\
(5)\end{array}$ & $\begin{array}{l}\text { VFD } \\
(6)\end{array}$ & $\begin{array}{l}\text { CFD } \\
\text { (7) }\end{array}$ & $\begin{array}{l}\text { VFD } \\
(8)\end{array}$ \\
\hline \pm 2 & 0.067 & - & 10 & - & 20 & - & 160 \\
\hline \pm 5 & 0.17 & - & 10 & - & 15 & - & 300 \\
\hline \pm 7.5 & 0.25 & 1 & - & 2 & - & 60 & - \\
\hline \pm 10 & 0.33 & - & 10 & - & 10 & - & 400 \\
\hline \pm 15 & 0.5 & 3 & 3 & 2 & 10 & 120 & 600 \\
\hline \pm 22.5 & 0.75 & 3 & 3 & 2 & 8 & 180 & 720 \\
\hline \pm 30 & 1.0 & 3 & 3 & 2 & 7 & 240 & 840 \\
\hline \pm 37.5 & 1.25 & 3 & 3 & 2 & 6 & 300 & 900 \\
\hline \pm 45 & 1.5 & 3 & 3 & 2 & 5 & 360 & 900 \\
\hline \pm 52.5 & 1.75 & 3 & 3 & 2 & 4 & 420 & 840 \\
\hline \pm 60 & 2.0 & 3 & 3 & 2 & 4 & 480 & 960 \\
\hline \pm 75 & 2.5 & 3 & 3 & 2 & 3 & 600 & 900 \\
\hline \pm 90 & 3.0 & 3 & 3 & 2 & 2 & 720 & 720 \\
\hline \pm 105 & 3.5 & 3 & 3 & 2 & 2 & 840 & 840 \\
\hline \pm 120 & 4.0 & 3 & 3 & 2 & 2 & 960 & 960 \\
\hline
\end{tabular}

Table 1 


\begin{tabular}{|c|c|c|c|c|c|c|}
\hline \multirow{2}{*}{$\begin{array}{l}\text { Specimen } \\
\text { type } \\
\text { (1) }\end{array}$} & \multicolumn{3}{|c|}{ Beams and Columns } & \multicolumn{2}{|c|}{ Joints } & \multirow{2}{*}{$\begin{array}{l}\text { Predicted } \\
\text { failure mode } \\
\text { (7) }\end{array}$} \\
\hline & $\begin{array}{l}\text { Member } \\
\text { (2) }\end{array}$ & $\begin{array}{l}\text { Flexural capacity, } \\
\text { kN-m (3) }\end{array}$ & $\begin{array}{l}\text { Story shear } \\
\text { force, } \mathrm{kN}(4)\end{array}$ & $\begin{array}{l}\text { Allowable joint } \\
\text { shear, MPa (5) }\end{array}$ & $\begin{array}{c}\text { Story shear } \\
\text { force, } \mathrm{kN}(6)\end{array}$ & \\
\hline \multirow{2}{*}{1} & Beam & $443.36(+), 887.55(-)$ & 453.7 & \multirow{2}{*}{$\begin{array}{l}7.03^{*} \\
6.33^{\#}\end{array}$} & \multirow{2}{*}{$\begin{array}{l}237.09^{*} \\
213.49^{\#}\end{array}$} & \multirow{2}{*}{$\begin{array}{l}\text { Joint shear } \\
\text { failure }\end{array}$} \\
\hline & Column & 454.02 & 342.7 & & & \\
\hline \multirow{2}{*}{2} & Beam & $628.38(+), 1058.43(-)$ & 564.8 & \multirow{2}{*}{$\begin{array}{l}7.15^{*} \\
6.55^{\#}\end{array}$} & \multirow{2}{*}{$\begin{array}{l}207.76^{*} \\
190.32^{\#}\end{array}$} & \multirow{2}{*}{$\begin{array}{l}\text { Joint shear } \\
\text { failure }\end{array}$} \\
\hline & Column & 373.12 & 281.6 & & & \\
\hline
\end{tabular}

Table 2 


\begin{tabular}{|c|c|c|c|c|c|c|c|c|}
\hline \multicolumn{3}{|c|}{$\begin{array}{c}\text { Parameters } \\
\text { (1) }\end{array}$} & $\begin{array}{l}\text { QS1 } \\
(2)\end{array}$ & $\begin{array}{c}\text { CFD1 } \\
(3) \\
\end{array}$ & $\begin{array}{c}\text { VFD1 } \\
(4) \\
\end{array}$ & $\begin{array}{c}\text { QS2 } \\
(5)\end{array}$ & $\begin{array}{c}\text { CFD2 } \\
(6) \\
\end{array}$ & $\begin{array}{c}\text { VFD2 } \\
(7) \\
\end{array}$ \\
\hline \multicolumn{3}{|c|}{ Failure mode observed } & Joint shear & Joint shear & Joint shear & Joint shear & Joint shear & Joint shear \\
\hline \multicolumn{3}{|c|}{ Max story drift applied } & $3.0 \%$ & $4.0 \%$ & $4.0 \%$ & $2.5 \%$ & $4.0 \%$ & $3.0 \%$ \\
\hline \multirow{2}{*}{$\begin{array}{l}\text { Peak story } \\
\text { response }\end{array}$} & \multicolumn{2}{|c|}{ Shear force } & $224.7 \mathrm{kN}$ & $258.6 \mathrm{kN}$ & $256.4 \mathrm{kN}$ & $180.5 \mathrm{kN}$ & $206.5 \mathrm{kN}$ & $230.9 \mathrm{kN}$ \\
\hline & \multicolumn{2}{|c|}{ Story drift } & $1.75 \%$ radian & $1.73 \%$ radian & $1.73 \%$ radian & $1.49 \%$ radian & $1.92 \%$ radian & $1.73 \%$ radian \\
\hline \multirow{6}{*}{\multicolumn{2}{|c|}{$\begin{array}{l}\text { Story shear } \\
\text { stiffness (kN/ \% } \\
\text { drift) at a story } \\
\text { drift (\%) }\end{array}$}} & 0.125 & 328.0 & 321.0 & 427.0 & 240.0 & 240.0 & 405.0 \\
\hline & & 0.5 & 221.4 & 235.8 & 261.7 & 181.1 & 190.8 & 244.6 \\
\hline & & 1.0 & 176.2 & 190.3 & 199.6 & 144.8 & 155.0 & 180.9 \\
\hline & & 1.5 & 143.6 & 162.2 & 163.8 & 118.8 & 135.6 & 137.7 \\
\hline & & 2.0 & 109.5 & 125.8 & 123.0 & 81.6 & 106.2 & 112.0 \\
\hline & & 2.5 & 84.1 & 98.7 & 94.5 & 61.1 & 81.2 & 86.0 \\
\hline \multirow{4}{*}{\multicolumn{2}{|c|}{$\begin{array}{l}\text { Average joint } \\
\text { shear strain at a } \\
\text { story drift (\%) }\end{array}$}} & 0.5 & 0.09 & 0.03 & 0.11 & 0.10 & 0.08 & 0.16 \\
\hline & & 1.0 & 0.30 & 0.13 & 0.30 & 0.25 & 0.21 & 0.33 \\
\hline & & 1.5 & 0.58 & 0.31 & 0.52 & 0.58 & 0.39 & 0.52 \\
\hline & & 2.0 & 0.86 & 0.55 & 0.88 & 1.40 & 0.57 & 0.76 \\
\hline
\end{tabular}

Table 3 

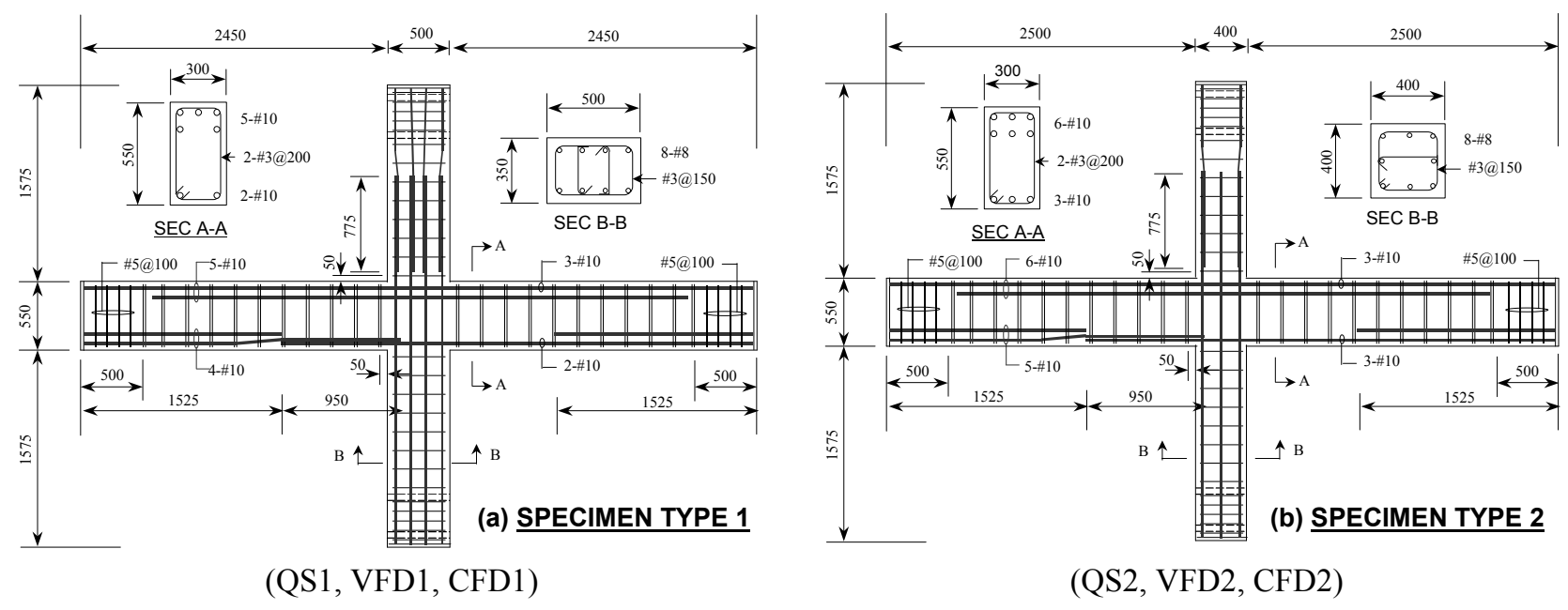

Figure 1 


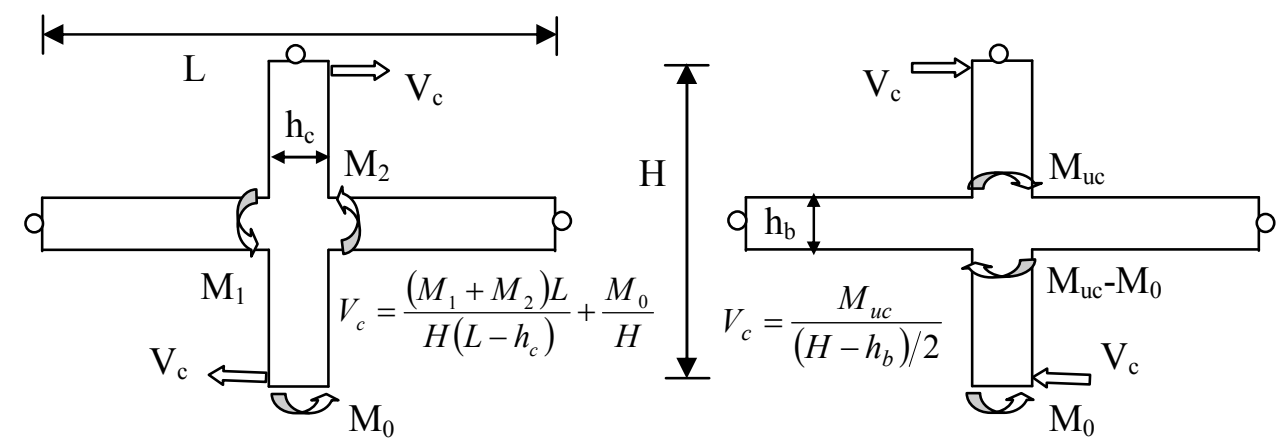

(a) Ultimate bending capacity reached in the beams

(b) Ultimate bending capacity reached in the column

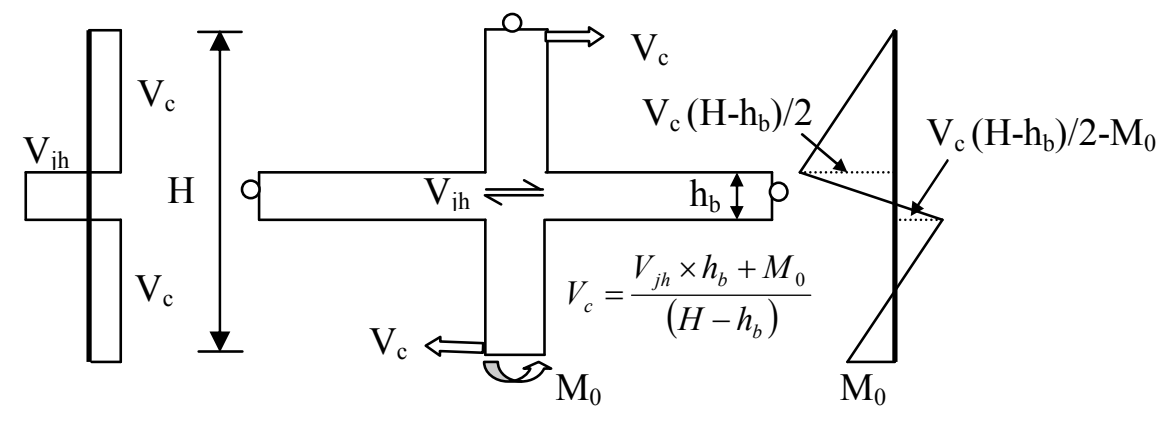

(c) Ultimate shear capacity reached in the joint

Figure 3 

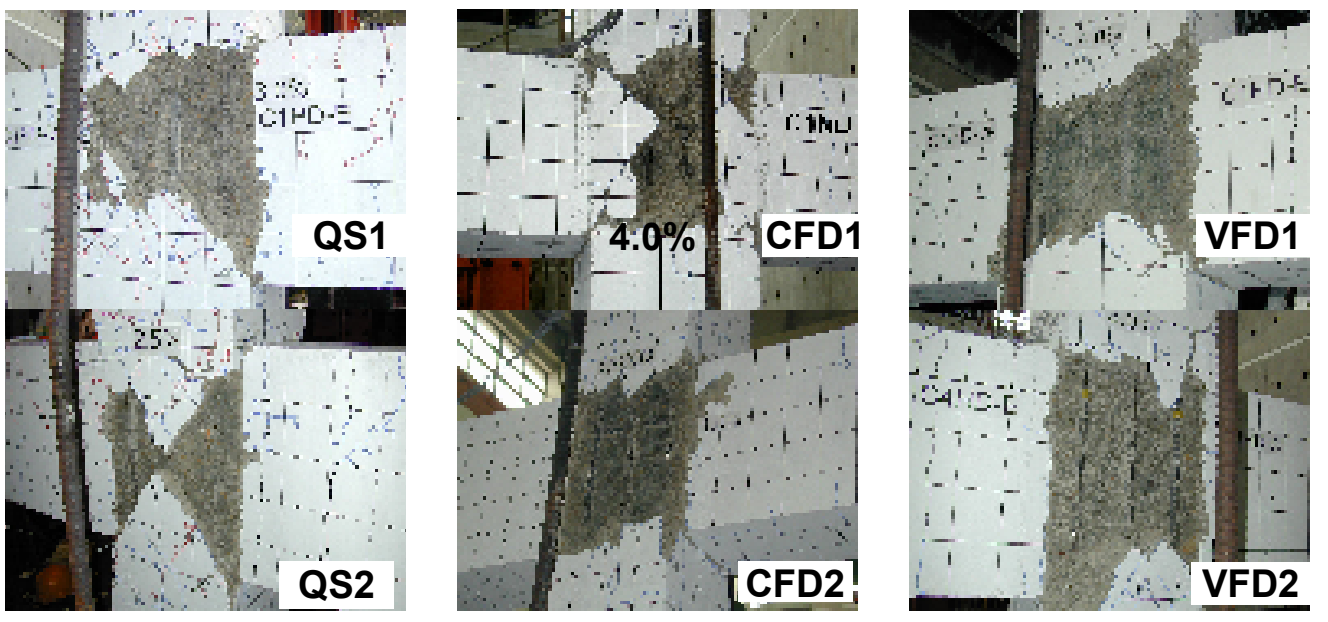

Figure 4 


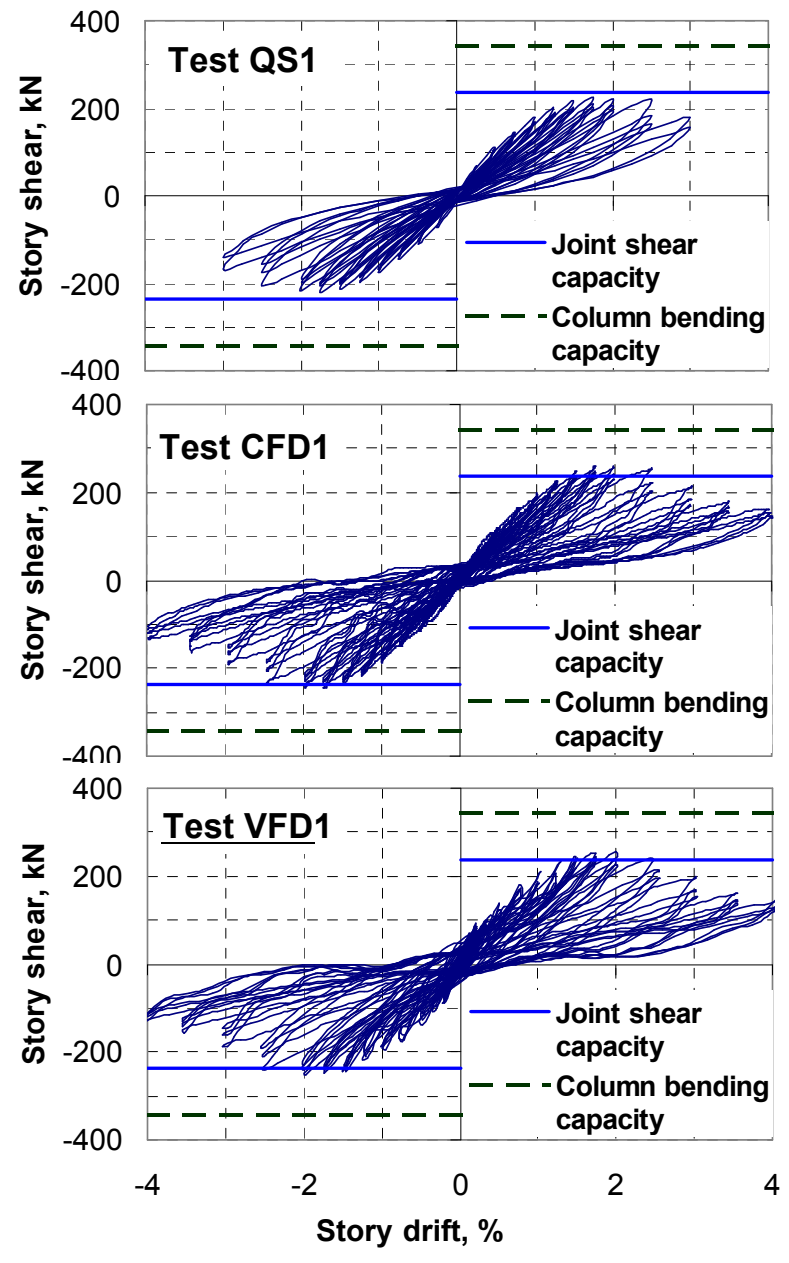

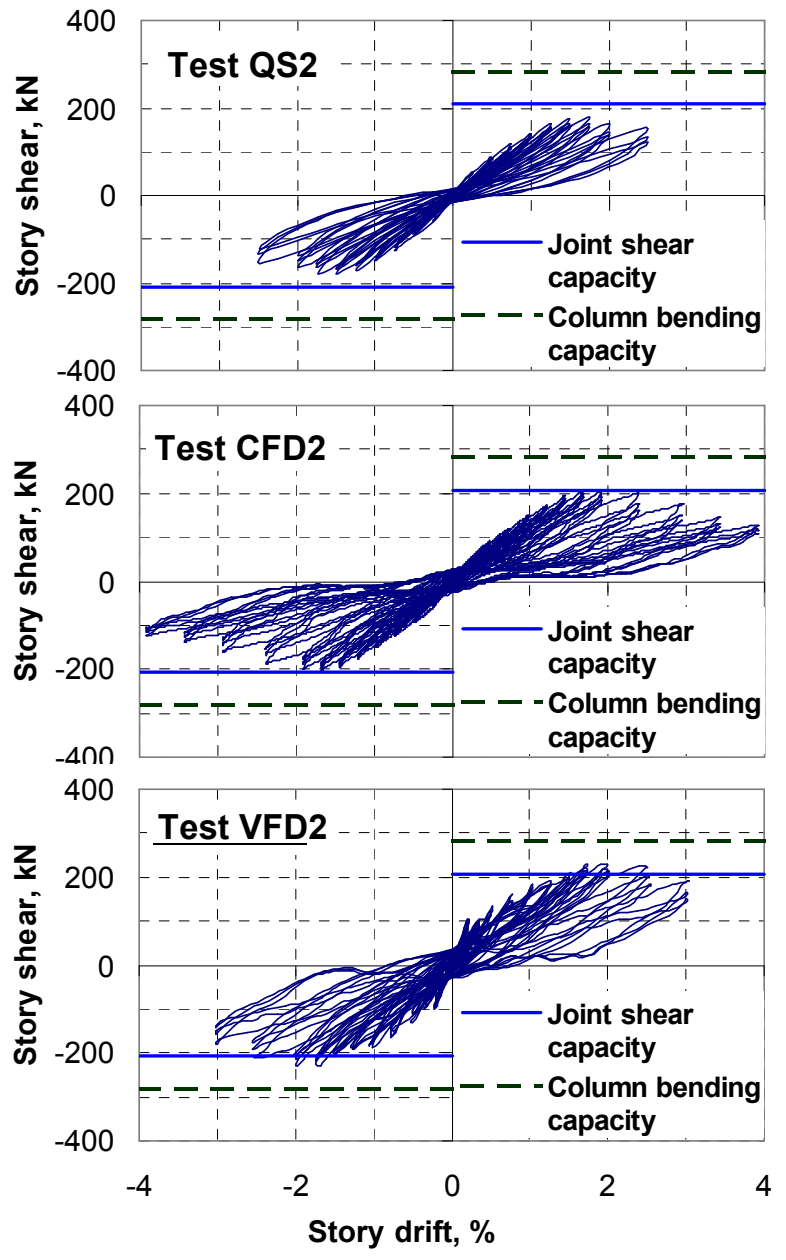

Figure 5 

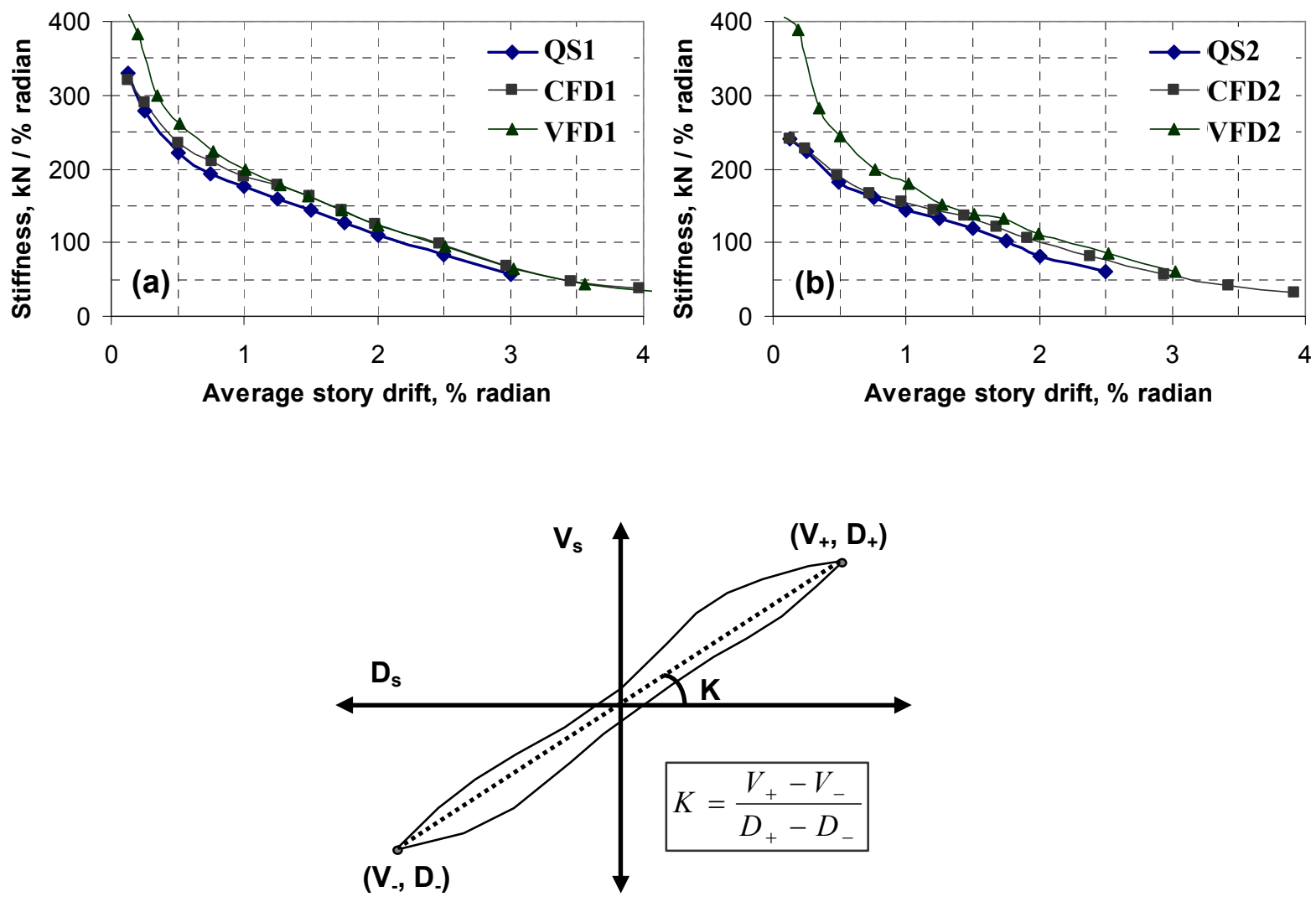

(c) Definition of shear stiffness

Figure 6 

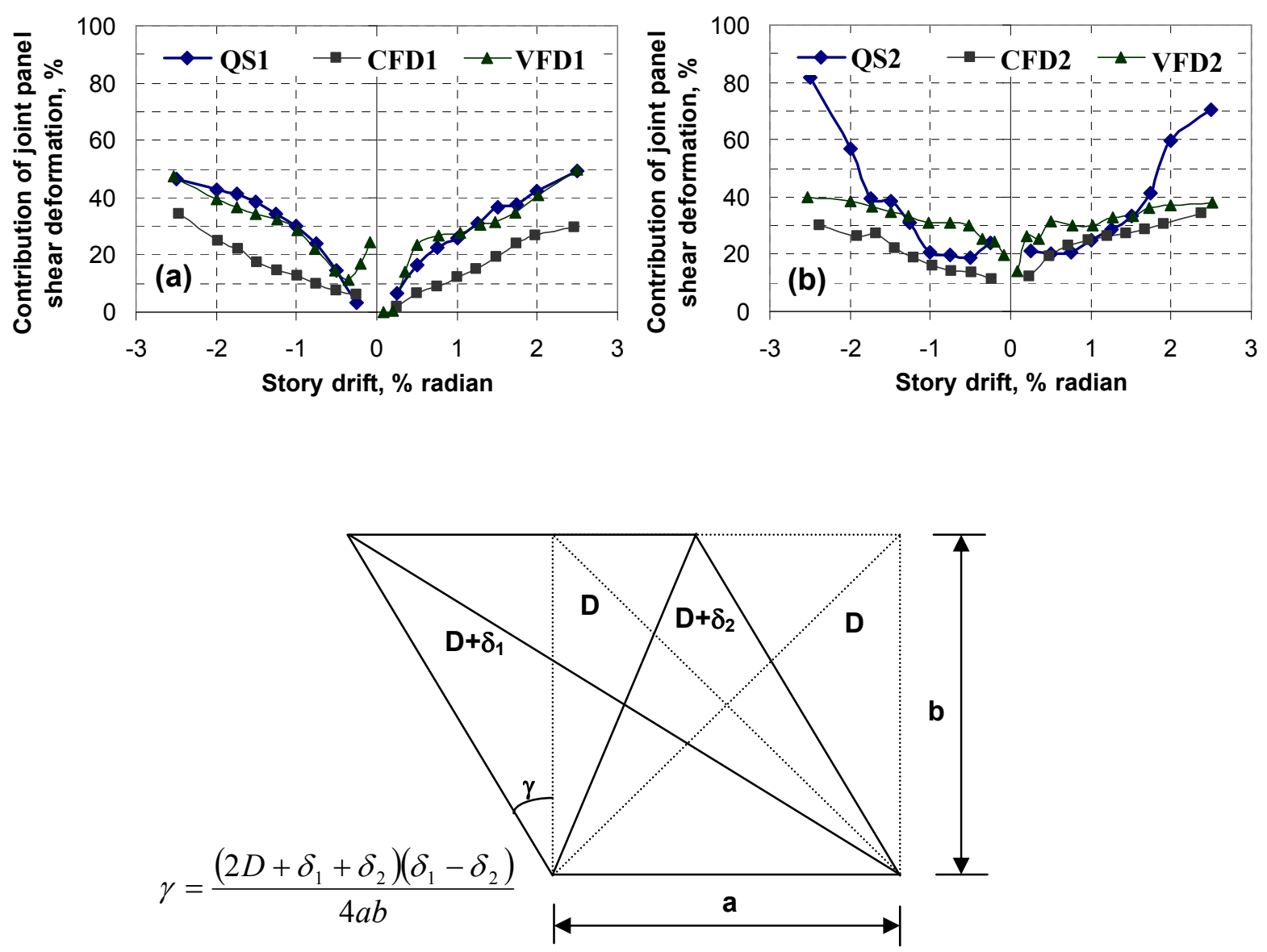

(c) Computation of joint panel shear deformation

Figure 7 

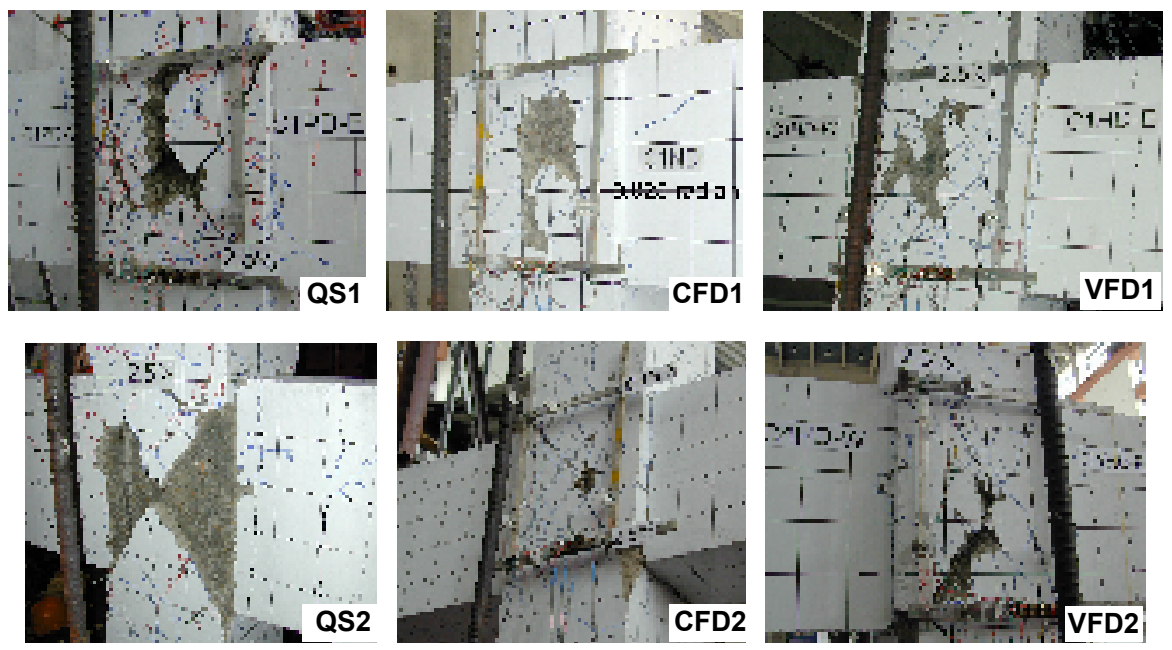

Figure 8 